Article

\title{
Single-Layer Pressure Textile Sensors with Woven Conductive Yarn Circuit
}

\author{
Gaeul Kim, Chi Cuong Vu(i) and Jooyong Kim *(1) \\ Department of Organic Materials and Fiber Engineering, Soongsil University, Seoul 156-743, Korea; \\ rkdmf3738@naver.com (G.K.); cuongvc287@gmail.com (C.C.V.) \\ * Correspondence: jykim@ssu.ac.kr; Tel.: +82-010-8720-0631
}

Received: 9 March 2020; Accepted: 13 April 2020; Published: 21 April 2020

Featured Application: The single-layer pressure sensor presented in this study serves as a stepping stone towards the development of cost-effective and scalable sensors for the industrial manufacturing process. The results show that the one-layer sensor has a high working performance and is thinner than multi-layer sensors. Thus, it is easy to apply it to robot control or human motion recognition fields.

\begin{abstract}
Today, $e$-textiles have become a fundamental trend in wearable devices. Fabric pressure sensors, as a part of $e$-textiles, have also received much interest from many researchers all over the world. However, most of the pressure sensors are made of electronic fibers and composed of many layers, including an intermediate layer for sensing the pressure. This paper proposes the model of a single layer pressure sensor with electrodes and conductive fibers intertwined. The plan dimensions of the fabricated sensors are $14 \times 14 \mathrm{~mm}$, and the thickness is $0.4 \mathrm{~mm}$. The whole area of the sensor is the pressure-sensitive point. As expected, results demonstrate an electrical resistance change from $283 \Omega$ at the unload pressure to $158 \Omega$ at the load pressure. Besides, sensors have a fast response time $(50 \mathrm{~ms})$ and small hysteresis $(5.5 \%)$. The hysteresis will increase according to the pressure and loading distance, but the change of sensor loading distance is very small. Moreover, the single-layer pressure sensors also show high durability under many working cycles $(20,000$ cycles) or washing times (50 times). The single-layer pressure sensor is very thin and more flexible than the multi-layer pressure sensor. The structure of this sensor is also expected to bring great benefits to wearable technology in the future.
\end{abstract}

Keywords: single-layer-textile pressure sensor; carbon nanotubes (CNTs); hysteresis; conductive wool yarns

\section{Introduction}

E-textile fibers have now been recognized as one of the important materials in the wearable technology field. More and more new $e$-textile fibers have been actively developed and applied in wearable devices [1-6]. Especially, as the convergence of fibers and IT technology has accelerated, many studies on electronic textile [7-10] and smart fibers [11-13] have been proposed, and a variety of products have been released [14]. However, $e$-textile fibers and wearable technologies still have many problems yet to be solved [15,16], especially in the pressure textile sensors field [17-20]. The pressure sensors based on smart fibers are necessary for all aspects of life, such as recognition of human activities, biosignal monitoring and healthcare. Those goals require the sensors to be lightweight, flexible, easy to use, and comfortable for the wearer. So, the development of compact pressure sensors [21-24] that can be a part of clothing has become a big challenge today. Most of the pressure sensors have a multi-layer structure with a low conductive layer as a spacer inserted between two high conductive 
layers in order to measure the levels of pressure [25-27]. For example, Atalay et al. [28] proposed the sensitive capacitive pressure sensor based on conductive fabrics and a microporous-dielectric layer. Pizarro et al. [29] presented an easy method to create a textile pressure sensor. Jeong et al. [30] studied a multilayer fabric pressure sensor for the real-time piezo-impedance imaging of pressure distribution. Chang et al. [31] developed a high-sensitivity and low-hysteresis- flexible pressure sensor based on carbonized cotton fabric. However, the multilayer structure will increase the thickness of the sensor and cause discomfort to the wearer. Therefore, this paper proposes a new structure composed of a one-layer sensor. Nonconductive fibers are converted to conductive fibers through the carbon nanotubes (CNTs) impregnation process. Then, the sensing layer is made by the intertwining of nonconductive fibers, conductive fibers, and electrodes. The results of experiments demonstrate that the one-layer-textile-pressure sensor is really thin $(0.4 \mathrm{~mm})$, lightweight, and more fit for wearable devices than the conventional multilayer structure. The characteristics of resistance and hysteresis of the fabricated sensor are analyzed in the paper. We also show an application of this sensor on the glove for monitoring finger motion.

\section{Sensor Design}

The conductive yarns are fabricated by impregnation to impart conductivity to the nonconductive wool yarns (about 10 yarns/sample). The impregnation ink is carbon nanotubes (CNTs) dispersed methyl ethyl ketone (MEK), which is easily agglomerated by the van der Waals force of the surface. Therefore, in order to ensure uniform dispersion, the CNT ink was stirred for at least $1 \mathrm{~h}$ at $700 \mathrm{rpm}$ by a mechanical stirrer and treated ultrasonically for avoiding incorporation of air bubbles by an ultrasonic machine (Figure 1a,b). As shown in Figure 1c,d, the wool yarns are impregnated in CNT inks and dried for $48 \mathrm{~h}$ in order to fix CNT particles adhering to the wool yarns. Using a precision LCR meter (Keysight E4980AL), we observed that the produced wool yarns have a resistance of about $7 \times 102 \Omega / \mathrm{cm}$.

(a)

Stirring

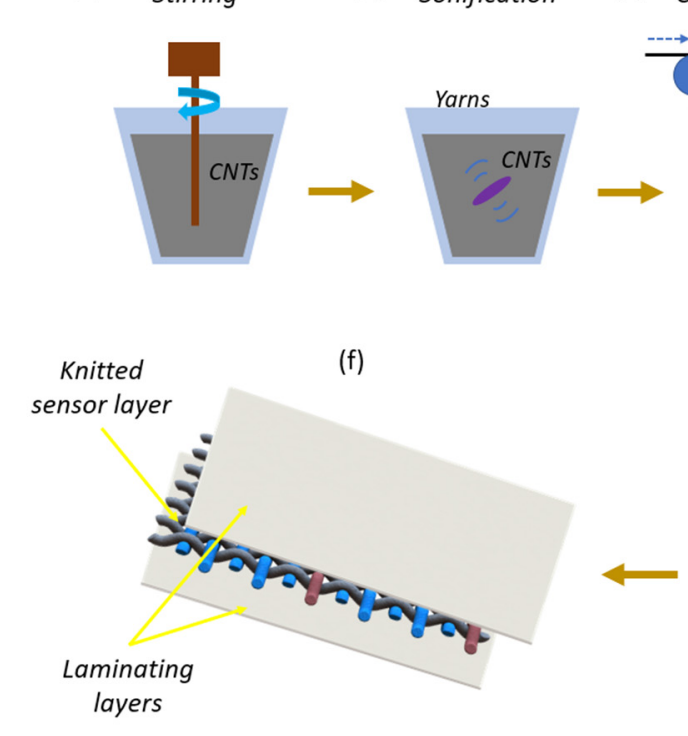

(b) Sonification

(c) CNT Impregnation

(d) Two-way drying (e)
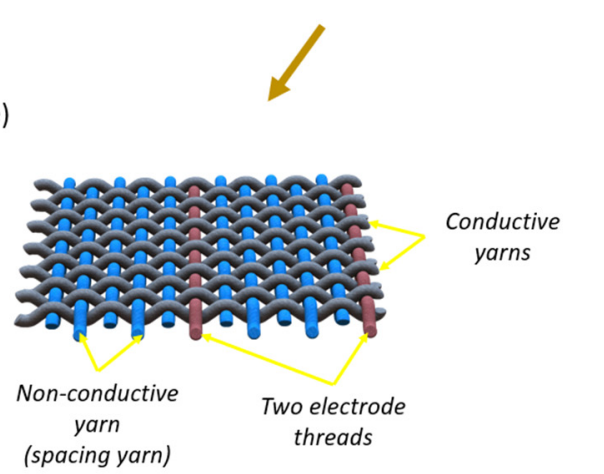

Figure 1. Fabrication process of conductive yarns consisting of (a) stirring CNTs, (b) sonification CNTs, (c) CNT-impregnation yarns, (d) drying CNT-yarns, (e) weaving sensor layer, and (f) the sensor with two laminating layers.

As shown in Figure 1e, single-layer pressure sensors are fabricated by combining electrode threads and spacing threads through intertwining with conductive wool yarns via a hand process on a weaving tool (from Woven on looms Ltd., Seoul, Korea) [32]. The electrode threads are made of 70 deniers (D) 
galvanized nylon plated yarn in a twist direction (S-twist) with a 140D metal plated gold yarn twined at a twisting rate of $10,000 \mathrm{rpm}$ during manufacturing. In the process of electrode threads, the metal plating chamber is set at a very high electrical resistance $(8.104 \Omega / \mathrm{m})$. Non-conductive PET 250D is used as the spacing yarns (about 10 yarns/sample). The sensor area is laminated by thermal pressing with a flexible thin film on both sides (Figure 1f) at a temperature of $135^{\circ} \mathrm{C}$ and a duration of $20 \mathrm{~s}$. These film layers cover the sensor surface and prevent CNT fall-off. The material used for laminating the sensor is a $100 \mu \mathrm{m}$ thin elastic film with $100 \%$ polyurethane (PU) from Sealon Ltd., Seoul, Korea. Because of the PU films, the sensor will no longer have a drape or feel of textiles normally, and it will have no breathability. However, the area size $(10 \mathrm{~mm})$ and the thickness $(0.4 \mathrm{~mm})$ of sensors are small; this can be accepted for the application in this paper. We suggest using other materials or structures for the cover layers (as highly stretchable PU/Silicone film, some holes on film) to improve the drape and breathability, but more experiments are needed for this. Finally, the one-layer-fabric pressure sensor of a small thickness of $0.4 \mathrm{~mm}$ and a size of $10 \times 10 \mathrm{~mm}$ is prepared.

\section{Results and Discussion}

\subsection{Conductive Wool Yarns}

A scanning electron microscope (SEM) is employed to characterize morphological changes of the wool yarns at different steps of the synthesis of the conductive fibers through the process proposed. Figure $2 \mathrm{a}, \mathrm{b}$ describes the fabricated sensors. Furthermore, Figure $2 \mathrm{c}-\mathrm{f}$ shows SEM images of the standard wool yarns with the magnified view showing no coating on the yarns and the coated yarns under high and low magnification with CNTs. The diameter of a single yarn is about $10 \mu \mathrm{m}$ and appears loosely twisted with ample free space between the microfibers. Conductive particles (CNTs) can be observed in the form of the thin coatings and stuck randomly onto wool yarns with an $80 \%$ coating area.

(a)

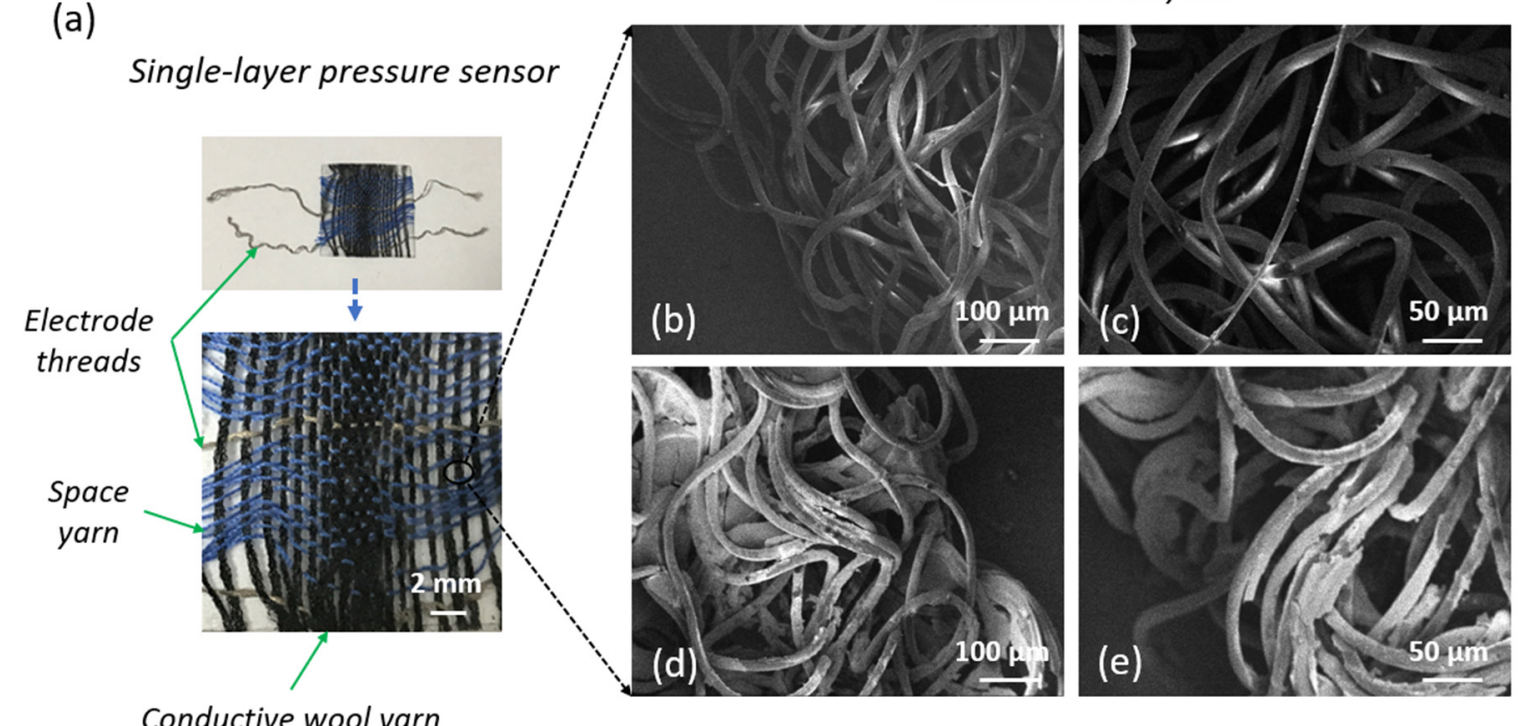

Figure 2. (a) Single-layer pressure textile sensor, (b) nonconductive wool yarn at $100 \mu \mathrm{m}$, (c) nonconductive wool yarn at $50 \mu \mathrm{m}$, (d) conductive wool yarn at $100 \mu \mathrm{m}$, and (e) conductive wool yarn at $50 \mu \mathrm{m}$.

\subsection{Electrical Properties}

To analyze the characteristics of sensors, we use a universal testing machine (UTM) from Dacell Co. Ltd., Seoul, Korea, and a source meter (Keysight B2902A). As shown in Figure 3a, sensor samples are placed above the sole and between the grips of the UTM machine. For the measurements of the 
electrical resistance, electrical wires connected directly to the two electrode threads of the samples by the grips. A constant source voltage applied to the samples during the test. Resistance and pressure are continuously measured when loading the force. At least five samples are tested, and the experiments are repeated 50 times in order to record average values, respectively.

The working principle (Figure 3b,c) of one-layer pressure sensors is based on sensing the change of electrical resistance when the distance between conductive particles (CNTs) changes in the conductive fibers, as well as between the CNTs and electrode threads. Equation (1) shows the electrical conduction mechanism under the loading of pressure where $R, \rho, l$, and A present the resistance, resistivity, fiber length, and cross-section area, respectively. As described in Figure $3 c, d_{0}$ is the initial distance between $\mathrm{CNTs}$, $\mathrm{d}$ is the distance between CNTs after pressuring, de 0 is the initial distance between CNTs and electrodes, and de is the distance between CNTs and electrodes after pressuring. When pressure is applied, these distances become closer $\left(\mathrm{d}<\mathrm{d}_{0}\right.$ and $\left.\mathrm{d}_{\mathrm{e}}<\mathrm{d}_{\mathrm{e}}\right)$; accordingly, the contact area becomes wider. Thus, total resistance will decrease.

$$
R=\rho \frac{l}{A}
$$

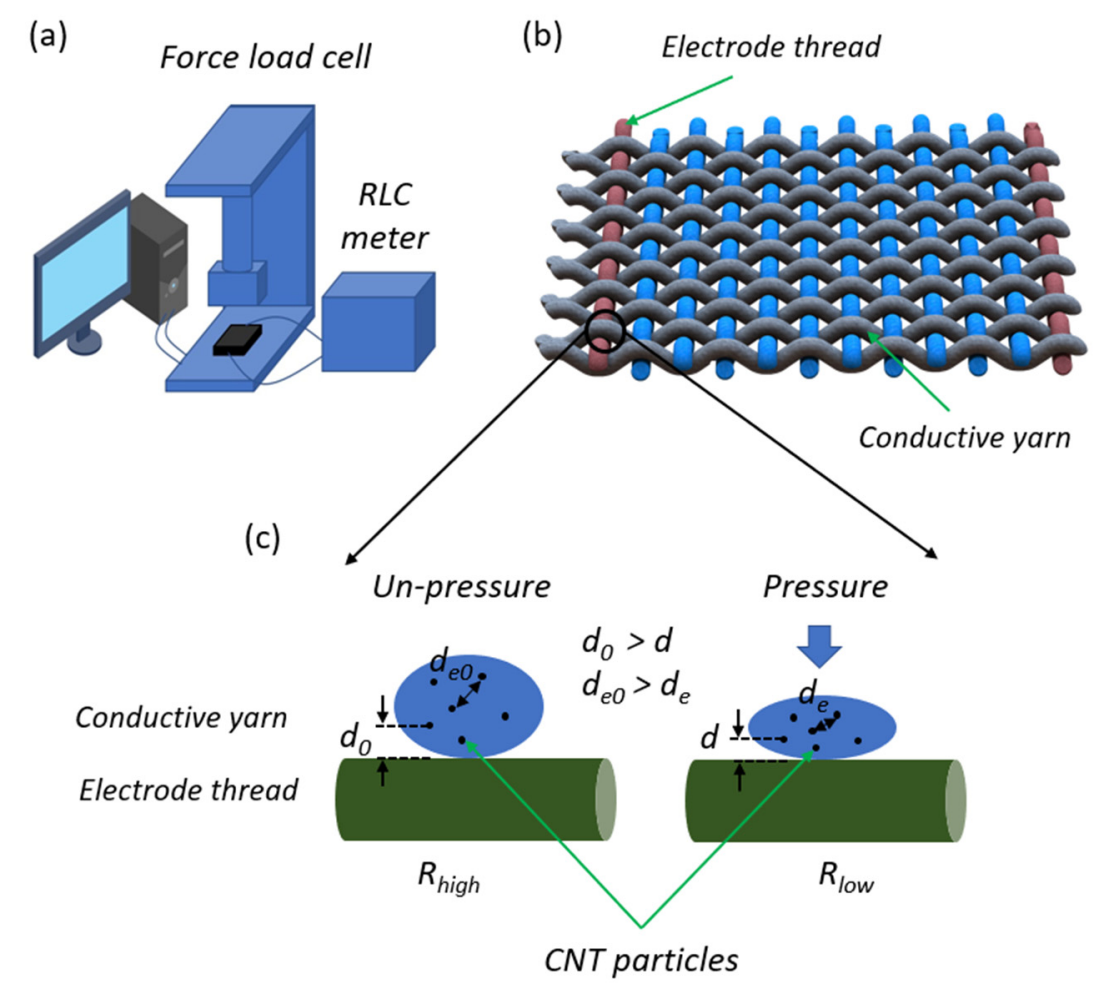

Figure 3. (a) Universal tensile machine (UTM), (b) sensing layer, and (c) working principle.

Figure 4 a shows a relationship between the pressure and resistance of sensors. Resistance changes from a maximum of $283.2 \Omega$ to a minimum of $158.7 \Omega$, following different levels of load pressures. It is clear that the sensors have a large working range from $0 \mathrm{kPa}$ to $1,000 \mathrm{kPa}$, and fit many applications. Figure $4 \mathrm{~b}$ shows a set of the current-voltage (I-V) graphical curves, which are used to define the operation of the sensor under different static pressures at $250 \mathrm{kPa}, 500 \mathrm{kPa}, 750 \mathrm{kPa}$, and $1000 \mathrm{kPa}$ within the system. The applied voltage from $-1.8 \mathrm{~V}$ to $1.8 \mathrm{~V}$ demonstrated an ohmic behavior of the sensors. The slope of I-V curves reduces with a decrease of pressure, indicating that an increase in applied pressure led to a decrease in the sensor's resistance. 
(a)

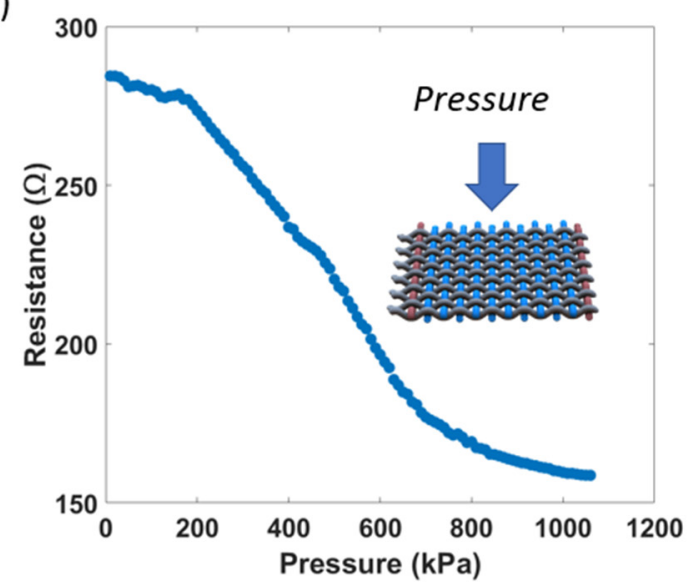

(b)

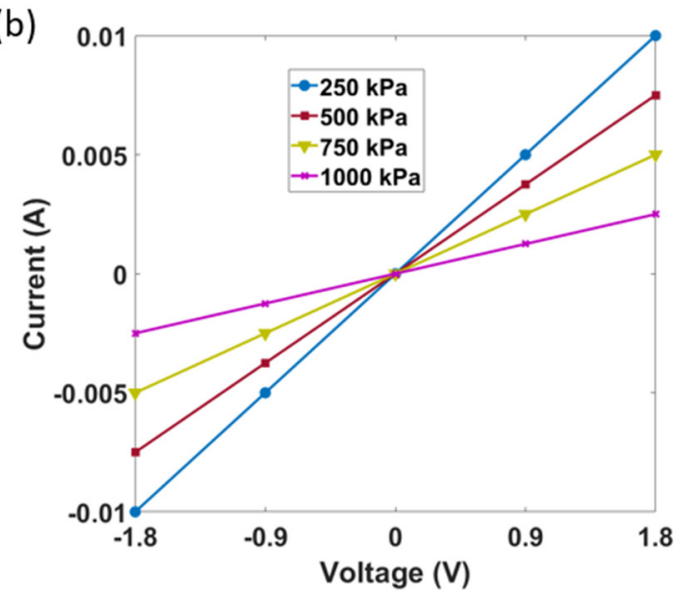

Figure 4. (a) Relationship of resistance and pressure, (b) I-V curves.

Figure 5 a describes the resistance of sensors after 100 loading cycles. The sensitivity decreases initially but stabilizes after some cyclic loading/unloading periods. The reason for this behavior is the deformation (permanent) in the structure under pressure leads to a change in the electrical response of the sensors. However, after 85 cycles, that deformation of the fibers remains stable, and the electrical output of the sensor becomes stable (Figure $5 b$ ). Response time is an important parameter that defines the time lag between an electronic input and the output signal. The response delay in the sensor is caused by the viscoelastic nature of wool yarns and the connectivity between the CNT coatings under pressure. As shown in Figure 5b, the fast response time is about $50 \mathrm{~ms}$. The fast connection time of conductive particles ensures the rapid electrical property of these sensors in a practical application.

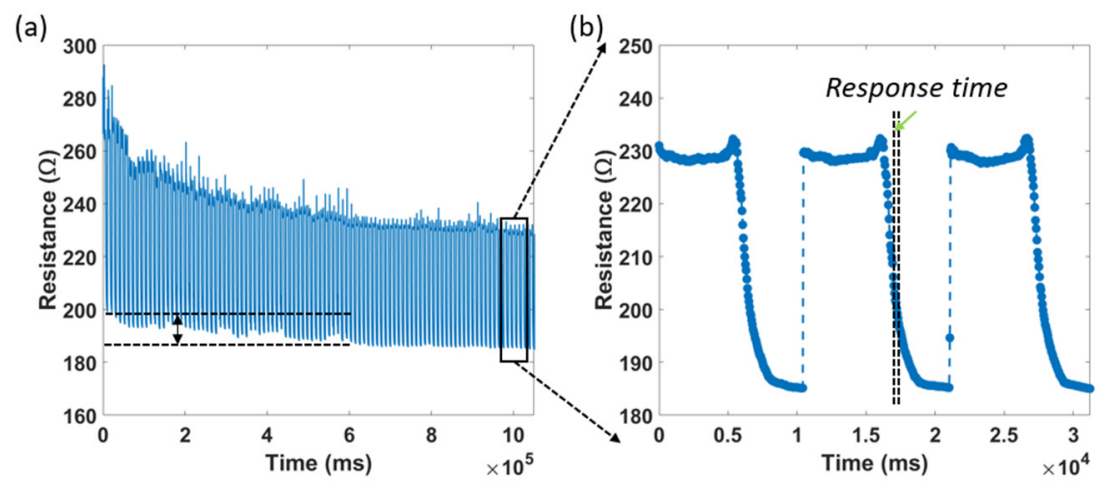

Figure 5. (a) Resistance change in 100 loading/unloading cycles and (b) Response time.

As described in Figure 6a, we also evaluated the hysteresis of the proposed sensor at different frequencies of $0.05 \mathrm{~Hz}, 0.1 \mathrm{~Hz}, 0.2 \mathrm{~Hz}, 0.5 \mathrm{~Hz}$, and $1 \mathrm{~Hz}$. With each frequency, the upper line presents the loading phase, and the lower line presents the releasing phase. Relative change-in-resistance values are logged during the loading (increasing pressure) and unloading (decreasing pressure), and the maximum hysteresis error of the sensor is found to be $5.5 \%$. It is clear that the higher pressure and faster removal speed will increase the hysteresis of the sensor. The results show that at a higher pressure and faster removal, the speed will increase the hysteresis of the sensor (Figure 6b). 
(a)

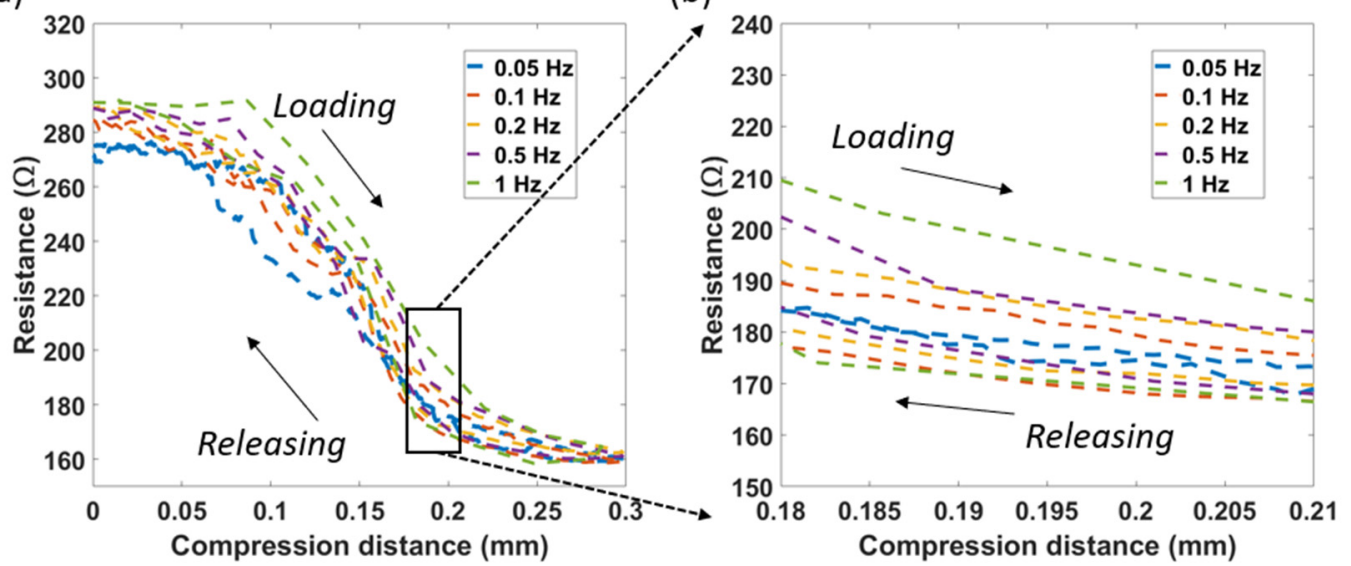

Figure 6. (a) Hysteresis at different frequencies in the compression from $0-0.1 \mathrm{~mm}$, and (b) hysteresis at different frequencies in the compression from $0.06-0.07 \mathrm{~mm}$.

In order to evaluate the dynamic durability of the sensors, we determined the stable electrical functionality and mechanical integrity during loading/releasing cycles. The experiment was performed in a lab-customized machine (UTM), and resistance was measured at every 100 cycles. We observed that uniform resistance changes of less than $7 \%$ were recorded after 20,000 loading/unloading cycles (Figure 7a). In the washing test, the samples were checked in a mini washing machine (LG-W0082) from Daewoong Co., Seoul, Korea. Each washing time had a duration of $10 \mathrm{~min}$, a squeezing time of $2 \mathrm{~min}$, and a drying time of $7 \mathrm{~min}$ at $100{ }^{\circ} \mathrm{C}$. The sensors demonstrated a small resistance change (less than $10 \%$ ) after 50 washing times (Figure $7 \mathrm{~b}$ ). This is significant for wearable applications.

(a)

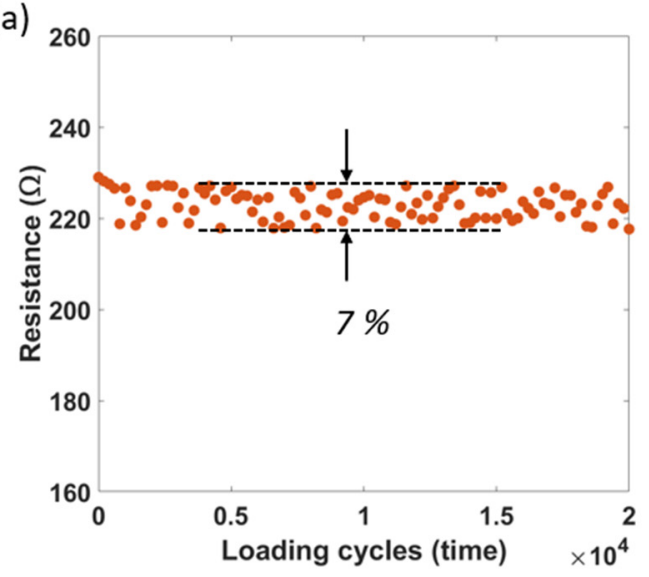

(b)

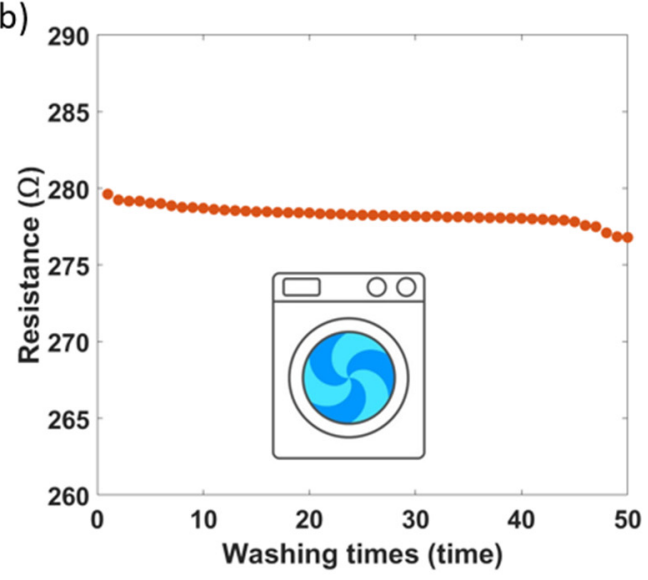

Figure 7. (a) Resistance after 20,000 loading/releasing cycles, and (b) resistance after 50 washing times.

Figure 8a shows the effect of temperature on the performance of the pressure sensor. The resistance change has a small range $(<4 \%)$ in the room temperature range of 20 to $30^{\circ} \mathrm{C}$. To decrease the effect of this factor, we suggest changing the sensor structure or covering all sides of the sensor with silicone. However, this method will also change the sensitivity of the sensors, so more experiments are needed in future work. In a comparison overview (Figure 8b), our sensors were found to be thinner than those of other studies [33-38], though they were a little bit thicker than those of [29] because of the laminating layers. A thin sensor will fit many wearable devices. 
(a)

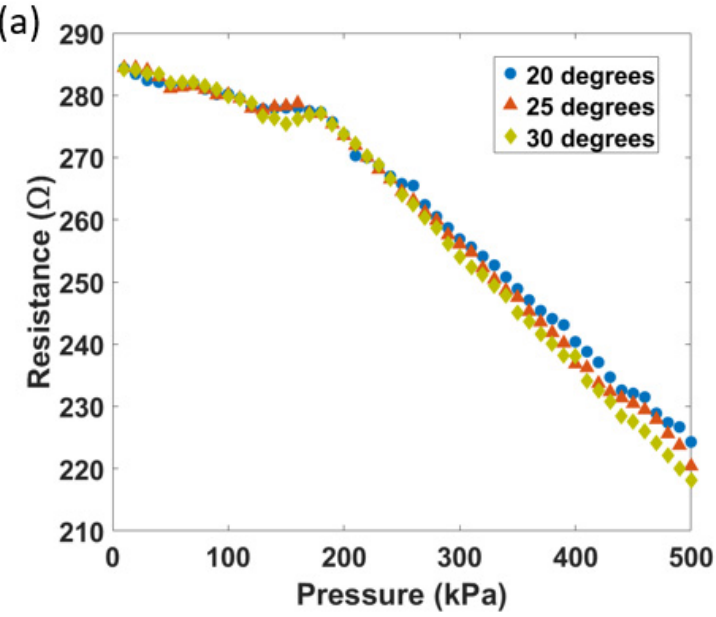

(b)

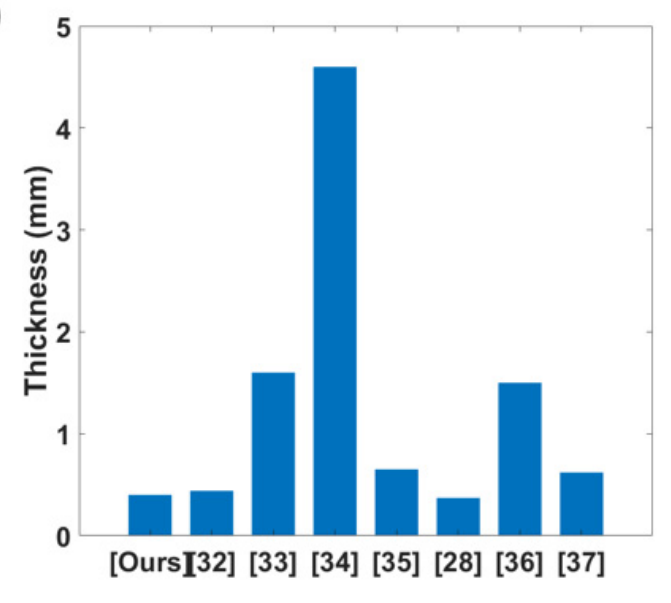

Figure 8. (a) Resistance change at different temperatures and (b) Comparison of the thickness with other studies.

\section{Smart Glove}

To demonstrate the potential of the one-single layer pressure sensors, the proposed sensor is integrated into a smart tactile glove (Figure 9a) in order to distinguish objects with different weights during a grasping task. We used a hot melt double-sided adhesive tape to attach the sensor onto the glove by heating it at $90{ }^{\circ} \mathrm{C}$ for $15 \mathrm{~s}$ (with an iron). Two electrode threads of the sensor were connected to two electrical wires of the Arduino Nano (5 V-16 Mhz) using a silver paste (from KLK Ltd., Jeonnam, Korea). As shown in Figure 9b, the hardware platform of experimental is an integrated circuit, composed of some main components such as Arduino, Bluetooth module, Micro SD Card, and a lipo-battery $(3.7 \mathrm{~V})$. Using a voltage divider circuit, the electrical resistance variation of the sensors has been converted into a voltage variation. Data are sampled and digitized and thus converted into digital values. For resolution reasons, mathematical mapping of voltage values between 0 to $5 \mathrm{~V}$ into digital values between 0 to 1023 (5/1023 0.005 V or $5 \mathrm{mV}$ per unit) has been made by pre-calculating the actual data. It is calculated to take about $0.01 \mathrm{~s}(10 \mathrm{~ms})$ to read an analog signal input, and a maximum reading rate is about 100 times per second. Subjects are instructed to grasp a paper water cup (Figure 9c) for an amount of time, and the electrical signal is continuously recorded. The weights of paper water cup are $110 \mathrm{~g}, 160 \mathrm{~g}, 210 \mathrm{~g}$, and $310 \mathrm{~g}$, respectively. Figure $9 \mathrm{~d}$ shows the amplitude signal during the scenarios. The change in electrical resistance is found to be higher when the subject grasps the heavier object. From the results, it is clear that this one-layer pressure sensor could be used in soft, wearable sensors or actuator applications for control purposes. 

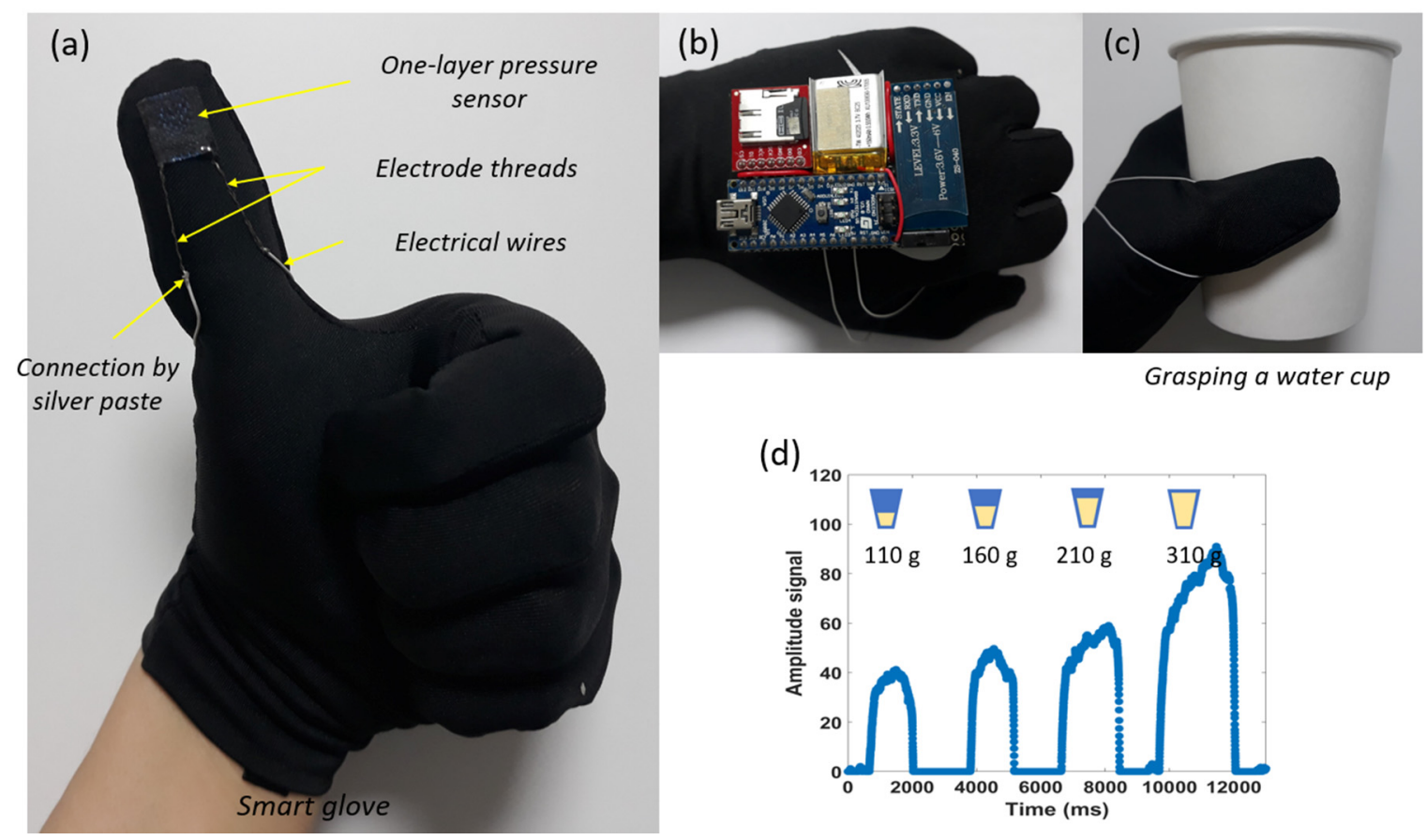

Figure 9. Smart glove application of the sensor, consisting of (a) structure of the sensing finger on glove, (b) hardware platform, (c) grasping a water cup, and (d) the change in signal amplitude when the subject grasps the different weights.

\section{Conclusions}

This paper presented a case of a single-layer pressure sensor fabricated by interweaving the conductive wool yarns and spacer thread (nonconductive) together in order to create the one-layer pressure sensor. The conductive wool yarns are converted from nonconductive yarns by being impregnated in CNT inks. Two electrodes of the sensor used two highly conductive threads. The electrical characteristics of the sensor are analyzed through experiments. Unlike the conventional pressure sensors (multi-layer structure), this sensor is thin $(0.4 \mathrm{~mm})$, extremely lightweight, and has a small hysteresis (5.5\%). We also demonstrated the application of the proposed sensor for detecting the grasping force via the smart glove. Such sensors can be utilized to sense the grasp action in robot control or human motion recognition.

Author Contributions: All authors have read and agree to the published version of the manuscript. Conceptualization, G.K., C.C.V., and J.K.; methodology, G.K., C.C.V., and J.K.; software, C.C.V.; validation, G.K., C.C.V., and J.K.; formal analysis, G.K., and C.C.V.; investigation, G.K.; resources, G.K., C.C.V., and J.K.; data curation, G.K., C.C.V., and J.K.; writing-original draft preparation, G.K., and C.C.V.; writing-review and editing, G.K., C.C.V., and J.K.; visualization, G.K., C.C.V., and J.K.; supervision, J.K.; project administration, J.K.; funding acquisition, J.K.

Funding: This research was funded by the National Research Foundation of Korea (NRF) grant number 2019R1A2C2005933 and Korea Display Industry Association(KDIA) grant number P0002397. The APC was funded by the National Research Foundation of Korea and Korea Display Industry Association.

Acknowledgments: This research was supported by the National Research Foundation of Korea (NRF) grant funded by the Korea government (MSIT) (No. 2019R1A2C2005933), and the Competency Development Program for Industry Specialists of the Korean Ministry of Trade, Industry, and Energy (MOTIE) operated by the Korea Institute for Advancement of Technology (KIAT) (No. P0002397, HRD program for Industrial Convergence of Wearable Smart Devices).

Conflicts of Interest: The authors declare no conflict of interest. 


\section{References}

1. Nag, A.; Mukhopadhyay, S.C.; Kosel, J. Wearable Flexible Sensors: A Review. IEEE Sens. J. 2017, 17, 3949-3960. [CrossRef]

2. Acar, G.; Ozturk, O.; Golparvar, A.J.; Elboshra, T.A.; Böhringer, K.; Yapici, M.K. Wearable and Flexible Textile Electrodes for Biopotential Signal Monitoring: A review. Electronics 2019, 8, 479. [CrossRef]

3. Liang, T.; Yuan, Y.J. Wearable Medical Monitoring Systems Based on Wireless Networks: A Review. IEEE Sens. J. 2016, 16, 8186-8199. [CrossRef]

4. Jayathilaka, W.A.D.M.; Qi, K.; Qin, Y.; Chinnappan, A.; Serrano-García, W.; Baskar, C.; Wang, H.; He, J.; Cui, S.; Thomas, S.W.; et al. Significance of Nanomaterials in Wearables: A Review on Wearable Actuators and Sensors. Adv. Mater. 2018, 31, 1805921. [CrossRef]

5. Di, J.; Zhang, X.; Yong, Z.; Zhang, Y.; Li, D.; Li, R.; Li, Q. Carbon-Nanotube Fibers for Wearable Devices and Smart Textiles. Adv. Mater. 2016, 28, 10529-10538. [CrossRef]

6. Vu, C.C.; Kim, J. Human Motion Recognition by Textile Sensors Based on Machine Learning Algorithms. Sensors 2018, 18, 3109. [CrossRef]

7. Ojuroye, O.O.; Torah, R.N.; Komolafe, A.O.; Beeby, S.P. Embedded Capacitive Proximity and Touch Sensing Flexible Circuit System for Electronic Textile and Wearable Systems. IEEE Sens. J. 2019, 19, 6975-6985. [CrossRef]

8. Castano, L.M.; Flatau, A.B. Smart fabric sensors and e-textile technologies: a review. Smart Mater. Struct. 2014, 23, 053001. [CrossRef]

9. Li, Y.; Li, Y.; Su, M.; Li, W.; Li, Y.; Li, H.; Qian, X.; Zhang, X.; Li, F.; Song, Y. Electronic Textile by Dyeing Method for Multiresolution Physical Kineses Monitoring. Adv. Electron. Mater. 2017, 3, 1700253. [CrossRef]

10. Wang, S.; Xuan, S.; Liu, M.; Bai, L.; Zhang, S.; Sang, M.; Jiang, W.; Gong, X. Smart wearable Kevlar-based safeguarding electronic textile with excellent sensing performance. Soft Matter 2017, 13, 2483-2491. [CrossRef]

11. Jeong, S.M.; Song, S.; Seo, H.-J.; Choi, W.M.; Hwang, S.-H.; Lee, S.G.; Lim, S.K. Battery-Free, Human-Motion-Powered Light-Emitting Fabric: Mechanoluminescent Textile. Adv. Sustainable Syst. 2017, 1, 1700126. [CrossRef]

12. Mao, C.; Zhang, H.; Lu, Z. Flexible and wearable electronic silk fabrics for human physiological monitoring. Smart Mater. Struct. 2017, 26, 095033. [CrossRef]

13. Tong, J.; Xu, Z.; Bian, Y.; Niu, Y.; Zhang, Y.; Wang, Z. Flexible and smart fibers decorated with Ag nanoflowers for highly active surface-enhanced Raman scattering detection. J. Raman Spectrosc. 2019, 50, 1468-1476. [CrossRef]

14. Koncar, V. Smart Textiles and Their Applications, 1st ed.; Woodhead Publishing: Cambridge, UK, 2016; pp. 329-374.

15. McLaren, R.; Joseph, F.; Baguley, C.; Taylor, D. A review of e-textiles in neurological rehabilitation: How close are we? J. NeuroEng. Rehabil. 2016, 13, 59. [CrossRef]

16. Bonfiglio, A.; Rossi, D.D. Wearable Monitoring Systems, 1st ed.; Springer: Boston, MA, USA, 2010; pp. 147-162.

17. Heo, J.S.; Eom, J.; Kim, Y.-H.; Park, S.K. Recent Progress of Textile-Based Wearable Electronics: A Comprehensive Review of Materials, Devices, and Applications. Small 2017, 14, 1703034. [CrossRef]

18. Gonçalves, C.; Silva, A.F.d.; Gomes, J.; Simoes, R. Wearable E-Textile Technologies: A Review on Sensors, Actuators and Control Elements. Inventions 2018, 3, 14. [CrossRef]

19. Hughes-Riley, T.; Dias, T.; Cork, C. A Historical Review of the Development of Electronic Textiles. Fibers 2018, 6, 34. [CrossRef]

20. Xu, F.; Li, X.; Shi, Y.; Li, L.; Wang, W.; He, L.; Liu, R. Recent Developments for Flexible Pressure Sensors: A Review. Micromachines 2018, 9, 580. [CrossRef]

21. Hu, J.; Meng, H.; Li, G.; Ibekwe, S.I. A review of stimuli-responsive polymers for smart textile applications. Smart Mater. Struct. 2012, 21, 053001. [CrossRef]

22. Tian, M.; Lu, Y.; Qu, L.; Zhu, S.; Zhang, X.; Chen, S. A Pillow-Shaped 3D Hierarchical Piezoresistive Pressure Sensor Based on Conductive Silver Components-Coated Fabric and Random Fibers Assembly. Ind. Eng. Chem. Res. 2019, 58, 5737-5742. [CrossRef]

23. Patel, S.; Park, H.; Bonato, P.; Chan, L.; Rodgers, M. A review of wearable sensors and systems with application in rehabilitation. J. NeuroEng. Rehabil. 2012, 9, 21. [CrossRef] [PubMed] 
24. Hirai, Y.; Suzuki, Y.; Tsuji, T.; Watanabe, T. Tough, bendable and stretchable tactile sensors array for covering robot surfaces. IEEE Int. Conf. on RoboSoft 2018, 1, 276.

25. Qiang, S.; Carey, T.; Arbab, A.; Song, W.; Wang, C.; Torrisi, F. Wearable solid-state capacitors based on two-dimensional material all-textile heterostructures. Nanoscale 2019, 11, 9912-9919. [CrossRef]

26. Chai, Z.; Zhang, N.; Sun, P.; Huang, Y.; Zhao, C.; Fan, H.J.; Fan, X.; Mai, W. Tailorable and Wearable Textile Devices for Solar Energy Harvesting and Simultaneous Storage. ACS Nano 2016, 10, 9201-9207. [CrossRef] [PubMed]

27. Wang, B.; Facchetti, A. Mechanically Flexible Conductors for Stretchable and Wearable E-Skin and E-Textile Devices. Adv. Mater. 2019, 31, 1901408. [CrossRef] [PubMed]

28. Atalay, O.; Atalay, A.; Gafford, J.; Walsh, C. A Highly Sensitive Capacitive-Based Soft Pressure Sensor Based on a Conductive Fabric and a Microporous Dielectric Layer. Adv. Mater. Technol. 2018, 3, 1700237. [CrossRef]

29. Pizarro, F.; Villavicencio, P.; Yunge, D.; Rodríguez, M.; Hermosilla, G.; Leiva, A. Easy-to-Build Textile Pressure Sensor. Sensors 2018, 18, 1190. [CrossRef] [PubMed]

30. Jeong, Y.J.; Kim, Y.E.; Kim, K.J.; Woo, E.J.; Oh, T.I. Multilayered Fabric Pressure Sensor for Real-Time Piezo-Impedance Imaging of Pressure Distribution. IEEE Trans. Instrum. Meas. 2019, 69, 565-572. [CrossRef]

31. Chang, S.; Li, J.; He, Y.; Liu, H.; Cheng, B. A high-sensitivity and low-hysteresis flexible pressure sensor based on carbonized cotton fabric. Sens. Actuators, A 2019, 294, 45-53. [CrossRef]

32. Weaving Kit. Available online: http://wovenonlooms.com/product/list.html?cate_no=24 (accessed on 2 April 2020).

33. Lou, C.; Wang, S.; Liang, T.; Pang, C.; Huang, L.; Run, M.; Liu, X. A Graphene-Based Flexible Pressure Sensor with Applications to Plantar Pressure Measurement and Gait Analysis. Materials 2017, 10, 1068. [CrossRef]

34. Qi, K.; Wang, H.; You, X.; Tao, X.; Li, M.; Zhou, Y.; Zhang, Y.; He, J.; Shao, W.; Cui, S. Core-sheath nanofiber yarn for textile pressure sensor with high pressure sensitivity and spatial tactile acuity. J. Colloid Interface Sci. 2020, 561, 93-103. [CrossRef] [PubMed]

35. Baldoli, I.; Maselli, M.; Cecchi, F.; Laschi, C. Development and characterization of a multilayer matrix textile sensor for interface pressure measurements. Smart Mater. Struct. 2017, 26, 104011. [CrossRef]

36. Lim, S.J.; Bae, J.H.; Jang, S.J.; Lim, J.Y.; Ko, J.H. Development of Textile-based Pressure Sensor and Its Application. Fibers Polym. 2018, 19, 2622-2630. [CrossRef]

37. Büscher, G.H.; Kõiva, R.; Schürmann, C.; Haschke, R.; Ritter, H.J. Flexible and stretchable fabric-based tactile sensor. Rob. Auton. Syst. 2015, 63, 244-252. [CrossRef]

38. Lim, S.J.; Bae, J.H.; Han, J.H.; Jang, S.J.; Oh, H.J.; Lee, W. Foldable and washable fully textile-based pressure sensor. Smart Mater. Struct. 2019. accepted. [CrossRef] 